\title{
Debunking 'Discourse Topic': Ideational Momentum and the Unpredictable Trajectory of Conversation ${ }^{1}$
}

\author{
MISCHA PARK-DOOB \\ University of Chicago
}

\section{Introduction}

There is a long-standing notion that in most instances of language use, the participants (whether speaking or writing) organize their production into coherent stretches identifiable as 'topics'. There is the further notion that these topics have easily definable beginnings and ends, allowing them to be labeled and strung together into a list or hierarchy which forms a useful schematic of what occurred during a given stretch of discourse. The preliminary rationale goes as follows:

\begin{abstract}
The conversationalists stop talking about 'money' and move on to 'sex'. A chunk of conversational discourse, then, can be treated as a unit of some kind because it is on a particular 'topic'. The notion of 'topic' is clearly an intuitively satisfactory way of describing the unifying principle which makes one stretch of discourse 'about' something and the next stretch 'about' something else, for it is appealed to very frequently in the discourse analysis literature. (Brown \& Yule 1983:70)
\end{abstract}

It was along these lines that Keenan \& Schieffelin (1976) introduced the 'discourse topic' as the "question of immediate concern", "a proposition (about which some claim is made or elicited)". This intuition seems to argue for parsing discourse in terms of separate topics, each identifiable by a single phrase or sentence.

As Brown \& Yule and many later analysts have recognized, such a view is far too simplistic. Their own concept of a "topic framework" is defined as the contextual framework "within which the topic is constituted", consisting of "activated features of context ... those aspects of the context which are directly reflected in the text, and which need to be called upon to interpret the text"

\footnotetext{
'This paper is basically a summary of my (unpublished) Master's thesis, Deconstructing 'topic': Relevance, consciousness, and the momentum of ideas (Park-Doob 2001). I'd like to thank my advisor David McNeill, and my colleagues in the McNeill Lab, including Karl-Erik McCullough, Chris Corcoran, Sue Duncan, KaLynne Harris, Nobuhiro Furuyama, Irene Kimbara, Fey Parrill, Mika Ishino, Amy Franklin, Arika Okrent, Nicla Rossini, and Gale Stam. Recent work has been supported by NSF KDI grant No. BCS-9980054, "Cross-Modal Analysis of Signal and Sense: Multimedia Corpora and Tools for Gesture, Speech, and Gaze Research", Francis Quek, P.I.
} 
(Brown \& Yule 1983:75). This formulation presents a few problems. In particular, the features of context which are salient for participants, at the time of interaction, may not all be later identifiable by the analyst, nor will they necessarily all be directly reflected in the "text". In an effort to go beyond both the text-based tradition and the speech-focused tradition, a growing body of work studying faceto-face narrative and conversation has been exploring the complex ways in which people communicate using the visuo-spatial and verbal modalities in synchrony (cf. McNeill 1992, papers in McNeill 2000). With a high-resolution audio/video recording of an interaction, the analyst has a view to the spontaneous hand gestures, facial expressions, body postures, and eye-gaze used in synchrony with speech by the participants, in addition to information about their physical environment. Given that even the best possible audio/video recording still fails to provide the analyst with a great deal of the information available at the time to the participants themselves, it seems clear that using just audio recordings and, worst of all, just written transcriptions to study conversation will provide limited insights (or even worse, result in false conclusions). Brown \& Yule's "topic framework", though fairly bogged down in a tradition of research using written transcripts, does at least highlight the critical necessity of examining both the fluid shared context in which any conversation is situated, as well as all available data from the conversation thus far, and points to the necessity for conversational participants to make their contributions relevant to the currently salient elements of the context and to the currently "activated" elements from the conversation thus far. Relatively few scholars have emphasized the importance of the interactively constructed, dialogic nature of language phenomena (Clark (1996) and Linell (1998) stand out favorably). Especially important is Rommetveit's (1974) concept of intersubjectivity in interaction, "in which there exists a partial complementarity, temporary reciprocity, and above all a shared consciousness among the interlocutors" (O'Connell \& Kowal, in press).

In this paper I will assume that participants in a conversation express ideas of some sort, and that their contributions are relevant, to a greater or lesser degree, to what has recently been, or is currently being, expressed or talked about. I use the word idea here in a purposefully vague sense, to mean any expressible notion, able to be communicated in any way. Jakobson (1960) provides a classic introduction to the multiple functions language is capable of handling simultaneously.

\section{Two modern attempts to improve on the 'discourse topic'}

Rather than parse discourse by labeling chunks with individual topics, a system has been devised by Barbara Grosz and colleagues (cf. Nakatani et al. 1995) that assumes segments of spoken discourse have a specific purpose underlying them, agreeing with Brown \& Yule's statement that "any consideration of topic involves asking why the speaker said what he said in a particular discourse situation" (1983:77). The system described in Nakatani et al. (1995) involves parsing a monologue into a hierarchical structure of large segments with broad purpose, each embedded with smaller nested subsegments of increasingly specific purpose. 


\section{Debunking 'discourse topic'}

The success of such a purpose hierarchy analysis requires that the segments and subsegments have clearly identifiable beginnings and ends, and that they each have clearly identifiable purposes and nested subpurposes. Each subpurpose must succeed in supporting the broader purpose(s) above it in the hierarchy.

Herb Clark differs from many analysts by making explicit the claim that all language is a form of joint action (Clark 1996). He acknowledges the cooperative, emergent, and opportunistically created nature of conversation, and wisely remarks that transcripts are only "footprints in the sand" (337), imperfect records of the dynamic processes of language in use. Naturally, he finds that "discourse topic is a static notion that doesn't do justice to the dynamic course of joint actions and what develops out of them" (342). To get around the question of 'topic' in interaction, he suggests joint actions are generally part of joint projects, which are structured hierarchically by smaller subprojects. What we get is a project hierarchy analysis which rather resembles the purpose hierarchies of Grosz and colleagues, but differs crucially in that the projects and subprojects are viewed as dynamic processes, not static objects with set purpose. In the coding scheme illustrated by Clark (343), each project and subproject requires a clear beginning and end, consciously agreed upon by the participants, and subprojects are placed at specific levels of embeddedness. Thus the two coding systems are similar in that each segment requires clear boundaries, and must have clear placement in a hierarchy. In the following sections we will discuss data that cooperate with these requirements, as well as data that illustrate their pitfalls.

\section{The experiment}

Before presenting data from recorded conversations, a few introductory remarks are in order. I originally recorded all the examples discussed below as part of a McNeill Lab study meant to elicit spontaneous gestures in two-person conversations (approximately 65 pairs of participants were recorded in 1999 and 2000; the participants cited here were all undergraduates at the University of Chicago). The present work grew out of my attempts to parse the results into purpose hierarchies inspired by Nakatani et al. (1995). Those attempts were done as a first pass, without special emphasis on examining gestures, and likewise I will not raise specific points about gestures in this paper. It should be noted, however, that all my judgments were made based on repeated observation of the video taped data, which allowed me to make qualitative observations about the participants' physical interaction with their environment and each other (including their gestures) and undoubtedly increased the accuracy of my judgments.

The experiment proceeded as follows: participant B remained outside the experiment room while participant $A$ examined a sheet of instructions pertaining to a plastic model city placed in front of his or her chair. The model was about three feet square and had five buildings: a movie theater, train station, church, and two houses (called \#33 and \#35). The instructions, which were the same for each pair of participants, outlined the following rather comical scenario: a family of intelligent wombats had taken up residence in the abandoned movie theater of the 
tiny town of Arlee, and it was the participants' job to recruit helpers from the town, flush out the wombats, capture them, and send them back to Australia. Participant A was instructed to describe the scenario to participant B, and together they were to design a creative plan of action (using the model city as a guide), and decide on what materials would be needed and how they would be used.

\section{When the methodology works, and when it fails ...}

Example (1) below is a small sample of a purpose hierarchy, the first draft of which was created by KaLynne Harris and me during the summer of 2000. Each segment is headlined by a verb phrase describing its purpose, and each line represents one intonation unit, a single communicative pulse which is also definable in prosodic terms (see Chafe 1994:57-70). Please refer to the transcription conventions listed at the end of the paper (paraphrased from Chafe 1994 and 1997, with a few additions based on McNeill Lab conventions). Given that the transcription is a mere shadow of the real interaction, it is mainly designed for maximum readability. I have attempted to keep the data relatively free of clutter, while still trying to provide hints to what the speech actually sounded like.

\section{(1) $6.5=$ discuss roles of $A$ and $B$ after wombats are rounded up in pen}

A \# an' só $==$,

A \# whíle,

6.5.1 = go into details about $B$ 's role

A ... since yóu're out front doing nothing but bànging your pót .. $\left\{\left\{^{\prime}[\mathrm{nn}]^{\prime}\right.\right.$ yer sh $\}$ -

B ..' $[$ [yeah.]'

A .. with your stíck,

6.5.1.1 = refute $A$, clarify role

$\mathrm{B}$ well I'm ${ }^{2}[\text { gonna }]^{2}$ be rùnning ${ }^{3}$ [thróugh. $]^{3}$

A ${ }^{2}[\text { you'll- }]^{2} \ldots{ }^{3}[\text { you'll- }]^{3}$ you'll- you'll come ${ }^{(a)}$ back ót ${ }^{(a)}{ }^{4}[\text { when- }]^{4}$

B ${ }^{4}[\text { yeah. }]^{4}$

A \# and,

A ... when thèy're thére.

A ... yóu kèep an èye on thèm an' l'll go wìth= the péople in hòuse-

A .. from e-

A w- thirty-thrèe or thirty-five,

6.5.2 = discuss calling authorities

A \# an' we'll cáll up like,

A ...(1.2) ánimal contròl ' $r$ whatéver.

6.6 = (unclear purpose)

A ... an' then

A ... we'll=",

6.5.2 (return) $=$ discuss calling authorities

A ... or $=$,

A ... y'know.

A ... the authórites in Austrália n' we'll make a phóne càll an' say we have these wómbàts that need to go back to Austrália or-

A \# (quite loud:) or we'll cáll a local zóo.

A ...(1.1) an' jùst be like we've càught these wómbàts and we néed you to còme táke thèm $==$

A like bàck to Austrália or whatèver. 
As can be seen, the above example fits fairly well into a purpose hierarchy analysis, for it consists mainly of a cinematic or play-by-play description, thoroughly dominated by participant A, of the plan for rounding up the wombats (see Park-Doob 2001 for a lengthier excerpt). Her description outlines a series of subtasks within subtasks, all geared toward the larger task of capturing the wombats, and all described in chronological order. Each subtask has an easily identifiable purpose functioning as a clear subpart of the larger mission goal, thus creating a hierarchy of tasks and nested subtasks, and so it is a straightforward matter to organize her speech into an identical hierarchy of purposes, each labeled according to what she is trying to describe. Participant B interferes very little, so this part of their dialogue behaves much like a monologue. Given that the discussion is also highly goal oriented, it's not surprising that it works well in a Groszstyle system, which in the case of Nakatani et al. (1995) was designed specifically to deal with goal oriented, task-driven monologue.

However, if intended for use with dialogues in general (and even many monologues), the treatment above poses some severe problems. First of all, the participants may begin a subsegment with some clear subpurpose to a broader purpose, but then lose track of this broader purpose as the subsegment progresses. This is due to our limited capacity to keep track of information and, in dialogic interaction, to our tendency towards unpredictable digressions and divergence (these issues will be discussed in detail below). The system of indentation is therefore potentially misleading: it places talk at absolute levels of nestedness, disregarding the fact that participants may lose track of the broader purpose, or digress repeatedly without ever returning to the previous discussion. In some conversations, we would be faced with a coding nightmare and find ourselves indenting beyond the right margin of the page! Fundamentally, speakers often shirk the broader purpose that led to their current discussion, even though that broader purpose may have been critical a few seconds before, and there may not have been a specific point of 'purpose shift' during the intervening talk. Since there may not be any absolute level of hierarchical nestedness in the minds of the participants, we have no justification in coding a transcript this way. The best we can do is note the relative changes in nestedness at their moment of occurrence, and allow that the resulting hierarchical relationship may lose credence as talk progresses.

The other critical problem with this analysis lies in its explicit requirement that talk be segmented into discrete, clearly delineated sections, each labeled with a specific 'purpose'. As we shall see, it is sometimes impossible to pinpoint where such segments begin or end. Clark's (1996) system of joint project hierarchies affords greater flexibility, but basically suffers from the same weaknesses: while participants may find themselves interacting jointly as if engaged in a particular project, there may be no clear spot where that particular project began if it has diverged smoothly away from the project of a few seconds before. Clark's hierarchical structure is also hampered by the same dependence on absolute levels of embeddedness. Consider the following extended excerpt, from a second pair of participants: 
(2) B ... \# an' máybe y'know while we're thère we còuld .. y'know, \# stày with thèm an',

... pàrty with thèm an',

... èat ${ }^{1}[\text { their fóo }=d \text { an', }]^{1}$

A ${ }^{1}$ brìng a few -$]^{1} \ldots$ bèers,

$B$... fr- yèah bring a few $b$ -

.. ingrátiàte oursèlves with thèe uh,

\# with the tòwn $=\ldots$ prèacher,

A ... ${ }^{1}[\mathrm{~m}-\mathrm{hm} .]^{1}$

B ... ${ }^{1}[\#]^{1}$ with a few bèers,

...@ ${ }^{2}[@ @]^{2} @ \ldots . .$.

A ${ }^{2}[@ @]^{2}$.............. \#

$\mathrm{B}$ mày-

.. İ don' know .. maybe we could gèt some diví=ne help,

.. to gèt rìd of the wó $=$ mbàts $=$.

${ }^{1}[\mathrm{~m}-]^{1}$

A ...oh ${ }^{1}[y]^{\prime}$ éah.

yòu're Cátholic áren't you.

$\mathrm{B} \#$ \#... yéah.

we could hà-

... like wè could .. s=èe if they had any hóly water on hànd an', A..@

B ... $\{w\}$ ait .. màybe they're demónic ${ }^{@} .$. wòm=bàts ${ }^{@}{ }^{1}[@ @ @ @]^{1}$

A ... ${ }^{\circledR}$ and crú ${ }^{\circledR}$ cifixes.

B..@

A..\#-

B ...\# and crúcifixes.

... and gár ${ }^{1}[\text { lic. }]^{1}$

A $\quad$ [thà $]^{1} t$ would be rèally gòod.

$\mathrm{B}$ \# gárlic we could ùse as bàit, mày ${ }^{2}[\text { be wómbàts like gárlic. }]^{2}$

A $\quad{ }^{2}$ [yéah $I b-. . I$ bèt th] ${ }^{2}$ ere're vámpìres lìving in the... abàndoned movie theater.

$B$ và ${ }^{3}[\text { mpire wòmbats. }]^{3}$

A \# ${ }^{3}$ ['cause you knów where- \#] $]^{3}$ where there're báts= there're

... an' ònce we find their còffins we can búrn'em.

vámpires tóo.

B ... yés $==$.

A or expóse'em to the light of dày.

\#

B $\ldots$ yés $==$

... ${ }^{1}$ [àbso]'lùtely.

A ... ${ }^{1}$ [yeah.] $^{1}$ 
$\mathrm{B}$ \# becàuse $\mathrm{y}^{\prime}$ knòw,

\# vàmpires and wòmbats are wònt to lìve in .. old abàndoned móvie theaters.

A ${ }^{2}[. . \mathrm{m}-\mathrm{hm} .]^{2}$

$\mathrm{B}^{2}[\#]^{2}$ in smàll tòwn $=$ USÀ.

A..@

B...@

\# um=,

A ... or-

$\ldots$ or hélicòpters.

\# maybe we could just còver the entíre-

\# like using hélicopters we could còver the entíre-

\# tówn with a hùge nét.

(continues...)

This excerpt poses a serious problem for an analyst wishing to parse it into a hierarchy of purposes, projects, or topics. While the participants actually do keep their discussion within the bounds of the task at hand, we face trouble once we try to parse it beyond this single over-arching project. Their talk begins with a discussion on partying with the townsfolk, and then follows a smoothly curving trajectory all the way to killing vampires. There are no 'kinks' in this trajectory. In other words, if we looked at any single moment during this stretch, the contributions before and after would all seem part of the same 'topic'. Then at the moment when participant A begins talking about helicopters, we have a sharp change easily identifiable by any traditional analysis as a point of 'topic shift'. The fundamental point is that the difference between partying with the townsfolk and killing vampires is certainly just as great as the difference between killing vampires and using helicopters. Clearly, the participants are able to drastically alter the course of their discussion without relying on specific points of major transition. A traditional analysis which cuts discourse into discrete, bounded segments will by definition focus on the boundaries, ignoring the fact that one of these same segments may experience subtle yet continuous internal changes which result in a net difference just as great as that found at the boundaries.

The constantly changing conversational trajectory illustrated in (2) is in no way abnormal. On the contrary, such a phenomenon is predictable given certain key aspects of human consciousness, which we examine next.

\section{The nature of consciousness}

For this discussion, we will follow Wally Chafe's model of consciousness:

At any given moment the mind can focus on no more than a small segment of everything it "knows." I will be using the word consciousness here to refer to this limited activation process. Consciousness is an active focusing on a small part of the conscious being's selfcentered model of the surrounding world. (Chafe 1994:28) 
Chafe goes on to describe certain key aspects of consciousness. First of all, consciousness has a focus which is "restless, moving constantly from one item of information to the next" (29). This movement is reflected linguistically in sequences of intonation units, as each unit "verbalizes the speaker's focus of consciousness at that moment" (63). Most of what is available to be focused upon will not be in a person's active consciousness at a given moment:

This limited activation allows a person to interact with the surrounding world in a maximally productive way, for it would hardly be useful to activate everything a person knew at once. Aside from the burden such a process might place on neural resources, most of that vast store of information would be irrelevant to one's interests at any particular time.

(29)

Consciousness also maintains, as a context for its current focus, a "periphery of semiactive information" (29). Once it is no longer in active focus, a given idea does not usually drop out of one's head immediately, but rather remains for a while in the semiactive realm. Each new focus then "find[s] coherence in the contexts provided by the surrounding semiactive information" (30).

Furthermore, consciousness requires an orientation, which gives individuals information about themselves with respect to the crucial domains of "space, time, society, and ongoing activity" (30). How a person's consciousness is oriented can be said to be a part of the peripheral context which aids the understanding of each new focus. Brown \& Yule (1983:60) suggest that interlocutors try to understand each other's utterances through as little processing as possible, and that they do this by way of an assumption of local interpretation (an interpretation based on the most recently put forth utterances and ideas). We can infer that a contribution intended to have a non-local interpretation will require more processing time and effort to produce and interpret. Chafe (1994:138) remarks that boundaries between "episodes" of talk are often observable as points of sudden reorientation, with the strength of the boundary depending on how much reorientation is necessary. It seems clear then that reorientation requires work. In order for a reorienting contribution to be coherent, the speaker must provide extra signals to aid the addressees in reorienting toward the new ideas, and the addressees must pick up on these signals and do the work of matching the speaker's new orientation.

\section{Chafe's notion of 'discourse topic'}

Equipped with an understanding of Chafe's notion of consciousness, we can move on to discuss his definition of 'discourse topic':

We can think of each ... topic as an aggregate of coherently related events, states, and referents that are held together in some form in the speaker's semiactive consciousness. A topic is available for scanning by the focus of consciousness, which can play across the semiactive material, activating first one part and then another until the speaker decides that the topic has been adequately covered for whatever purpose the speaker may have in mind. (Chafe 1994:121) 
While this notion is appealing, and a great deal of real conversation may occur this way, Chafe seems to assume that conversations always have such a structure: "One of the things that seems intuitively true of conversations is that they focus on different topics ... . at different times, moving from one topic to another" (Chafe 1994:121). The problem, similar to what we faced with the frameworks of Herb Clark (1996) and Barbara Grosz and her colleagues (Nakatani et al. 1995), is that we will fail to identify clear 'topics' in actual stretches of discourse if the talk proceeds haphazardly and without clear points where any speaker deems the talk has "adequately covered" the ideas whose full discussion required organization within a 'topic'. After a speaker initiates discussion that he or she hopes will remain within a particular bounded realm of semiactive consciousness, the participants have limited resources with which to ensure the mutual continued awareness of those boundaries, and they may not have even agreed on the boundaries in the first place. During the course of "scanning" across the semiactive material with their ever-restless foci of consciousness, one or more participants may begin to lose track of the originally intended boundaries, allowing their understanding of the "semiactive realm" of current discussion to gradually move farther and farther from the original. Since consciousness has only a single, constantly restless focus and a limited ability to maintain peripheral attention on salient pieces of semiactive information, staying 'on topic' requires the tough work of continually re-foregrounding ideas as they pass out of active consciousness, become faded in semiactive consciousness, and begin to slip out of a speaker's control.

In the realm of semiactive consciousness, certain elements may remain highly salient while others fade away. Physical context is particularly important in this respect, as it plays the main role in maintaining orientation in space and time. A constant physical orientation provides the necessary stimuli by which many other elements of an interaction remain in the foreground of attention. For example, in (2) above, the participants allow their talk to meander without any clear 'topic' structure, yet all of their discussion remains confined to the realm of the model city and the task at hand. Their very physical presence in the lab, among its lights and cameras, and the model city placed before them, keep them constantly oriented towards these physical aspects and each other. This orientation, in turn, keeps the directed task near the foreground of their consciousness. What we have then are conversations which illustrate how the conscious mind is both constrained by its orientation and simultaneously left free to make innovative and unpredictable associations on the fly. Orientation can be thought of as a stabilizing, guiding force, from which our cognitive creativity may attempt to spring free.

\section{Ideational momentum}

In order to properly understand the coherent flow of ideas in examples such as (2) above, regardless of whether there appears to be an identifiable 'topic', I propose the notion that ideas have inertia, and that the act of communicating ideas imparts conversation and the ideas themselves with a sort of ideational momentum. The 
notion of momentum implies that the participants' contributions will carry both magnitude and direction, meaning that the trajectory of conversation can be altered either gently or violently, in any direction, resulting in a path which maps a much more descriptive picture of the course of a conversation than a simple framework of topics divided by boundaries.

Chafe has recognized that a conversation can attain "momentum", but he describes this momentum as something that "sustains topics" (Chafe 1994:127). This is one of the things momentum is capable of, but I would rather describe it in more general terms, as the strength with which ideas cause conceptual associations to other ideas, whether or not these associations are 'on topic'. The human mind seems to involuntarily draw links from one idea to the next, in a sort of internal "association engine". Once communicated in a conversation, an idea becomes foregrounded in the consciousnesses of the participants, who each interpret it in their own way. Depending on the momentum it imparts to each person, the participants energetically or weakly draw associations to various related ideas, including those which may not be at all relevant to the current discussion. In many interactional situations, participants are expected to ignore these irrelevant associations and base their contributions not only on what was just in focus, but also on salient pieces of information still in semiactive consciousness. The likelihood of divergence increases with the number of participants, both because of the increased variety in conceptual associations being made, and because the separate consciousnesses of separate minds, even as they continually reorient to each other, still have a limited ability to synchronize.

Ideational momentum and a flexible notion of conversational trajectory still account for traditional points of 'topic shift': they are simply the points where the momentum and trajectory change most suddenly. What have so often been called 'topics', we could assert, are fundamentally segments of smoothly changing ideational momentum. Whether or not the discussion remains 'on topic' throughout one of these segments is a consequence not wholly under the participants' control. A successful 'topic' in Chafe's sense requires an actual desire to maintain, for a time, a discussion with conscientiously maintained boundaries, and also depends on the ability of the participants to overcome potentially divergent contributions.

We noted earlier that Chafe observed stronger or weaker boundaries between sections of talk to be points of stronger or weaker reorientation, respectively. To account for this observation, we can claim that the degree of required reorientation, and the amount of effort exerted, is proportional to the degree of change in ideational momentum. Given the limited attention of consciousness, shifts in trajectory that occur gradually over large periods of time will be less noticeable (and require less sudden reorientation) than shifts that occur quickly, and they may not even be perceived by the participants. Along the same lines, a shift from silence to talk forces the magnitude of ideational momentum to shift suddenly from zero to a positive value, requiring reorientation. When the momentum has reached zero (as can occur during long silences or when the participants seem to "run out of steam"), equal effort is required to restart talk in any direction-there 


\section{Debunking 'discourse topic'}

is no longer a bias towards following the trajectory of the most recent talk. As expected, points of zero momentum are typical places for speakers to suddenly alter the discussion. Park-Doob (2001) describes many cases not shown here, but one spot in (2) above should suffice to illustrate the point. It is hard to depict on paper, but right before A brings up the idea of helicopters, the participants "run out of steam", a feeling which B intones with his low $u m=$. Participant A takes up this cue and cautiously starts discussion down a new trajectory. Her repetition of or - signals her efforts to begin reorienting herself and her interlocutor to deal with brand new material.

\section{Conclusion}

'Discourse topics', in any sense, are simply not a requirement for coherent language use. It takes special effort to bring about and maintain them, and their use arises out of a social need to discuss specific groups of ideas thoroughly and completely, rather than out of a cognitive requirement that discourse proceed this way. With the concept of ideational momentum, I have attempted to describe how participants in conversation navigate from one idea to the next, following a trajectory that is largely unpredictable, yet illustrates many creative cognitive associations and processes that seem to form an integral part of human consciousness.

\section{Transcription conventions (paraphrased from Chafe 1994 and 1997)}

Primary accent (pitch deviation accompanied by loudness or lengthening)

Secondary accent (for syllables with qualitatively less-than-primary stress)

.. A very brief (on the order of 0.1 seconds or less) pause or break in timing

... A "typical" pause (between around 0.1 and 0.7 seconds for most speakers, at times up to one second in places where this is still unmarked)

...(2.4) A longer pause (measured in seconds)

\# A pause coinciding with an audible intake of breath

- Marks points where letters have been omitted from normal orthography in order to represent the pronunciation more accurately (beyond a generic reading in American English); also used for standard contractions

$=$ Lengthening of the preceding vowel or consonant sound (ignoring "silent" elements in the orthography; for example, 'there=' 'yeah=' 'uh=')

, Marks the end of an intonation unit as having a terminal contour which is not sentence-final

Marks the end of an intonation unit as having a sentence-final falling pitch

- Marks an intonation unit or word as aborted or suspended

$i$ ? Encloses stretches of speech that have a rising pitch contour typical of a yes-no question (includes many instances of "up-talk")

(a) A pulse of laughter or giggling

(a) Encloses words spoken while laughing or giggling

${ }^{2}[]^{2}$ A segment of speech that overlaps with another segment uttered by a different speaker (indexed by common superscripts).

\{\} Encloses a doubtful transcription 


\section{Mischa Park-Doob}

\section{References}

Brown, Gillian \& George Yule. 1983. Discourse Analysis. Cambridge: Cambridge University Press.

Chafe, Wallace. 1994. Discourse, Consciousness, and Time: The flow and displacement of conscious experience in speaking and writing. Chicago: The University of Chicago Press.

Chafe, Wallace. 1997. Polyphonic topic development. In Talmy Givón (ed.) Conversation: Cognitive, communicative and social perspectives. Amsterdam: John Benjamins.

Clark, Herbert H. 1996. Using Language. Cambridge: Cambridge University Press.

Givón, Talmy (ed.). 1997. Conversation: Cognitive, communicative and social perspectives. Amsterdam: John Benjamins.

Jakobson, Roman. 1960. Closing statement: Linguistics and poetics. In Thomas A. Sebeok (ed.) Style in Language. Cambridge, MA: The MIT Press. Excerpts reprinted in Adam Jaworski \& Nikolas Coupland (eds.) The Discourse Reader. New York: Routledge.

Jaworski, Adam \& Nikolas Coupland (eds.). 1999. The Discourse Reader. New York: Routledge.

Keenan, Elinor Ochs \& Bambi Schieffelin. 1976. Topic as a discourse notion: A study of topic in the conversations of children and adults. In Charles N. Li (ed.) Subject and Topic. New York: Academic Press.

Linell, Per. 1998. Approaching Dialogue: Talk, interaction and contexts in dialogical perspectives. Amsterdam: John Benjamins.

McNeill, David. 1992. Hand and Mind: What gestures reveal about thought. Chicago: The University of Chicago Press.

McNeill, David (ed.). 2000. Language and Gesture. Cambridge: Cambridge University Press.

Nakatani, Christine H., Barbara J. Grosz, David D. Ahn \& Julia Hirschberg. 1995. Instructions for annotating discourses. Technical Report TR-21-95, Center for Research in Computing Technology, Harvard University.

O'Connell, Daniel C. \& Sabine Kowal. In press. Psycholinguistics: A half century of monologism. American Journal of Psychology.

Park-Doob, Mischa. 2001. Deconstructing 'topic': Relevance, consciousness, and the momentum of ideas. Unpublished Master's thesis, University of Chicago.

Rommetveit, Ragnar. 1974. On message structure: A framework for the study of language and communication. London: Wiley.

5610 Hammersley Rd

Madison, WI 53711

maparkdo@alumni.uchicago.edu 